\section{Prognostic factors for visual acuity improvement after intravitreal triamcinolone injection}

S Shulman, JR Ferencz, G Gilady, Y Ton and E Assia

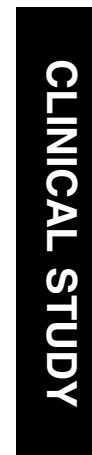

Keywords: intravitreal triamcinolone; macular oedema; diabetic retinopathy

\section{Introduction}

Intravitreal triamcinolone acetonide injection (IVTA) is being increasingly used to treat patients with macular oedema resulting from a variety of conditions such as diabetes, ${ }^{1,2}$ retinal vein occlusion, ${ }^{3,4}$ pseudophakia, ${ }^{5}$ various types of uveitis, ${ }^{6}$ radiation retinopathy, ${ }^{7}$ and idiopathic cystoid macular oedema (CME). ${ }^{8}$ It has also been tried in patients with choroidal neovascular membranes associated with age-related macular degeneration, ${ }^{9}$ presumed ocular histoplasmosis syndrome, or choroiditis.

A significant percentage of patients (up to $50 \%$ ) develop side effects, the most common being a rise in intraocular pressure (IOP) that may or may not be transient. ${ }^{10}$ Other possible complications of IVTA include cataract progression and - although rarely - retinal tears, retinal detachment, and endophthalmitis. ${ }^{11,12}$

The injection usually results in clinical improvement, expressed as a reduction in macular thickness seen on fundoscopic examination and on optical coherence tomography (OCT). In most cases, fluorescein angiography reveals a reduction in vascular leakage as well. In many patients, however, despite resolution of the macular oedema, visual acuity does not improve.

The purpose of this study was to identify prognostic factors for visual acuity improvement with IVTA, so that patients who are less likely to benefit from this procedure need not be exposed to unnecessary risks.
Department of Ophthalmology, Sapir Medical Center, Meir Hospital, Kfar Saba, Israel

Correspondence:

S Shulman,

Department of

Ophthalmology, Sapir

Medical Center,

Meir Hospital, Kfar Saba 44281, Israel Tel: + 972544618722 Fax: + 97297472427.

E-mail: shirishu@aol.com

Received: 27 December 2005

Accepted in revised form: 2 April 2006 Published online: 12 May 2006

This paper was presented in part in the Association for Research in Vision and Opthalmology annual meeting, Fort Lauderdale, FL, USA, May 2005

The authors have no proprietary interest in the materials used in this study
Tchernikovsky Street, 


\section{Methods}

We reviewed the medical records of all patients who had been treated by IVTA for macular oedema in our department between 1 November 2002 and 31 January 2004.

Exclusion criteria included bilateral injections, a previous ocular operation (except cataract operation), and any evidence of active or previous ocular inflammation.

The collected data included demographic information, medical and ocular history (especially previous operations or laser treatments), visual acuity and IOP on presentation, complete ocular examination, and recent fluorescein angiography (up to 2 weeks before the treatment).

Triamcinolone acetonide (Kenalog, Bristol-Myers Squibb, Italy) had been administered unilaterally to each patient under sterile conditions in the operating room, Following topical anaesthesia (lidocaine gel) and anterior chamber paracentesis, $4 \mathrm{mg}$ of triamcinolone acetonide $(0.1 \mathrm{ml})$ was injected through the pars plana into the vitreous.

Patients had been re-examined on the day after the injection and again 1 week and 1 month after the injection and at monthly intervals thereafter. All examinations had included best-corrected visual acuity measurement (performed using Snellen chart by masked examiners in standard conditions), slit-lamp biomicroscopy, Goldman applanation tonometry, and ophthalmoscopy.

In the present study, 'improvement' was defined as gain of at least two Snellen chart lines. We divided the patients into two groups: those who showed improvement in visual acuity (group 1) and those whose visual acuity was unchanged or worsened (group 2).

CME was defined as retinal thickening associated with intraretinal cyst formation as detected on slit-lamp opthalmoscopy using 60 or $78 \mathrm{D}$ lens and leakage with areas of dye pooling in the typical flower-petal pattern in fluorescein angiography as detected by an independent examiner. Diffuse macular oedema was defined as retinal thickening without cyst formation. The term pseudophakic macular oedema was used in the presence of macular oedema within 6 months postcataract operation in the absence of diabetic retinopathy, vein occlusion, or any other condition that may cause macular oedema.

The preinjection parameters compared between the two groups of patients were age, gender, aetiology of macular oedema, visual acuity, clinical findings on slit-lamp and fundus examinations, and findings on fluorescein angiography. For statistical analyses, we used
SPSS for Windows (SPSS, Chicago, IL, USA). Categorical variables were analysed using the $\chi^{2}$ test. Continuous variables were compared using Student's $t$-test.

\section{Results}

A total of 57 patients (39 men and 18 women, ranging in age from 39 to 90 years, with a mean age \pm SD of $67.7 \pm 10.5$ years), whose medical files recorded unilateral treatment with IVTA during the abovementioned period, were divided into two groups on the basis of the IVTA outcome, as described in Methods. The mean age \pm SD of the 27 patients in group 1 and of the 30 patients in group $2(65.8 \pm 11.8$ and $68.9 \pm 11.05$ years, respectively) did not differ significantly. The mean changes in visual acuity were a gain of 2.2 Snellen lines in group 1 and a loss of 1.5 Snellen lines in group 2. Other relevant medical and ocular informations in the two groups of patients, before and after IVTA, are recorded in Table 1.

Initial visual acuity ('good', 'moderate', or 'poor') and aetiology of macular oedema (diabetic, venous occlusionassociated, or pseudophakic) did not differ between the two groups.

Improvement was achieved by significantly more pseudophakic patients than in phakic patients (Table 1).

Clinical evidence of CME was present in 22 patients and diffuse retinal thickening in 35 . Of the eyes with clinical CME, improvement was seen in $70 \%$, compared to an improvement in $30 \%$ of eyes with diffuse retinal thickening; this difference was statistically significant $(P=0.04)$. Neither the degree (mild, moderate, or severe) of macular thickening (not shown) nor the presence of hard exudates (Table 1) differed significantly between the two groups.

Improvement was seen in significantly fewer patients who underwent macular laser treatment before IVTA than in those who did not (Table 1).

Of the 32 patients who underwent fluorescein angiography, improvement was seen in significantly more who were found to have CME than in those found to have diffuse retinal thickening (Table 1).

Sample sizes were too small for reliable determination of the influence of capillary nonperfusion on visual acuity improvement.

\section{Discussion}

IVTA is being increasingly used to treat macular oedema of various aetiologies. Its mechanism of action, however, is not fully understood. Adamis ${ }^{13}$ suggested a common pathway in macular oedema pathology involving increased vascular permeability as well as chronic inflammation characterized by adhesion of leukocyte to 
Table 1 Medical and ocular factors before and after injection in the two groups

\begin{tabular}{|c|c|c|c|c|}
\hline \multirow[b]{2}{*}{ Factors } & \multirow{2}{*}{$\begin{array}{l}\text { Pre-IVTA } \\
\text { No. (\%) } \\
57(100)\end{array}$} & \multicolumn{2}{|c|}{ Post-IVTA } & \multirow[t]{2}{*}{ P-value } \\
\hline & & $\begin{array}{c}\text { Group } 1 \text { (improved) } \\
\text { No. (\%) } \\
27(47)\end{array}$ & $\begin{array}{c}\text { Group } 2 \text { (not improved) } \\
\text { No. }(\%) \\
30(53 \%)\end{array}$ & \\
\hline \multicolumn{5}{|l|}{ Visual acuity } \\
\hline Good $(>6 / 15)$ & $5(9)$ & $1(20)$ & $4(80)$ & \\
\hline Moderate (6/15-6/60) & $39(68)$ & $21(54)$ & $18(46)$ & NS \\
\hline Poor $(<6 / 60)$ & $13(23)$ & $5(38)$ & $8(62)$ & \\
\hline \multicolumn{5}{|l|}{ Diagnosis } \\
\hline Diabetic ME & $43(75)$ & $19(44)$ & $24(56)$ & \\
\hline ME owing to BRVO & $7(12)$ & $5(71)$ & $2(29)$ & NS \\
\hline Pseudophakic ME & $4(7)$ & $3(75)$ & $1(25)$ & \\
\hline \multicolumn{5}{|l|}{ Type of oedema (clinical exam.) } \\
\hline Diffuse thickening & $35(61)$ & $11(31)$ & $24(69)$ & $0.04^{\mathrm{a}}$ \\
\hline CME & $22(39)$ & $15(69)$ & $11(31)$ & \\
\hline \multicolumn{5}{|l|}{ FA leakage pattern } \\
\hline Diffuse leakage & $11(34)$ & $1(9)$ & $10(91)$ & $0.02^{\mathrm{a}}$ \\
\hline CME & $21(66)$ & $14(67)$ & $7(33)$ & \\
\hline \multicolumn{5}{|l|}{ Lens } \\
\hline Phakic & $37(65)$ & $14(38)$ & $23(62)$ & $0.046^{\mathrm{a}}$ \\
\hline Pseudophakic & $20(35)$ & $13(65)$ & $7(35)$ & \\
\hline \multicolumn{5}{|l|}{ Previous laser treatment } \\
\hline Yes & $35(61)$ & $13(37)$ & $22(63)$ & $0.02^{\mathrm{a}}$ \\
\hline No & $22(39)$ & $14(63)$ & $8(37)$ & \\
\hline \multicolumn{5}{|l|}{ Presence of hard exudates } \\
\hline Yes & $18(32)$ & $7(39)$ & $11(61)$ & NS \\
\hline No & $39(68)$ & $22(56)$ & $17(44)$ & \\
\hline \multicolumn{5}{|l|}{ Capillary nonperfusion on FA } \\
\hline Yes & $3(9)$ & $2(67)$ & $1(33)$ & NS \\
\hline No & $29(91)$ & $15(52)$ & $14(48)$ & \\
\hline
\end{tabular}

BRVO, branch retinal vein occlusion; CME, cystoid macular oedema; FA, fluorescein angiography; IVTA, intravitreal triamcinolone acetonide injection; $\mathrm{ME}$, macular oedema; NS, not significant.

aStudent's $t$-test.

retinal vessels and their migration into the retina. These and other inflammatory pathways are known to be affected by steroids.

Negi et al $^{1}$ reported a significant improvement in visual acuity after IVTA injection. In some cases, however, despite the reduction in macular oedema observed on fundus examination and on OCT measurements, visual acuity does not improve. Sutter et $a l^{14}$ reported that in $45 \%$ of their patients with macular oedema refractory to laser treatment, there was no change in visual acuity after IVTA. The characteristic features of patients with macular oedema who are most likely to benefit from IVTA have not been defined.

In this study, we attempted to identify the factors associated with improvement in visual acuity, as distinct from objective measures of macular oedema improvement. Our main goal was to identify the group of patients most likely to improve after IVTA injection, and thus avoid subjecting patients to the procedure if they are unlikely to benefit from it.

The most important finding was a significant difference in outcome between patients with CME and patients with diffuse macular leakage. Detection of CME, either by clinical examination or by fluorescein angiography, was a positive prognostic factor for visual acuity improvement. The difference might be associated with breakdown of the blood-retina barrier in CME compared to the retinal thickening associated, for example, with focal leaking microaneurisms. Restoration of the blood-retina barrier after IVTA might explain the 
favourable results in patients with CME, irrespective of the aetiology.

The chances of improvement were significantly higher in pseudophakic than in phakic patients $(P=0.046)$. It is possible that potential improvement in the phakic group is offset by progression of cataract. This is not likely to be the case in our patients, however, as none of them showed significant cataract progression within the 3month follow-up period of our study. The phenomenon might also be explained in terms of breakdown of the blood-retina barrier during previous cataract surgery.

A trend towards a better chance of improvement was noted in eyes in which the initial visual acuity was moderate $(6 / 15-6 / 60)$ rather than good or bad $(54 \%$ compared to 20 and $38 \%$, respectively). This was not statistically significant, however, possibly because the number of patients in the 'good' visual acuity group was small.

Our finding that visual acuity improvement was not significantly influenced by the aetiology of the macular oedema supports the possible existence of a common pathogenic pathway for macular oedema of various aetiologies, as mentioned previously. ${ }^{13}$

The duration of time macular oedema and visual loss existed was not known for all our patients as some of the patients presented or referred to us with pre-existing macular oedema of unknown duration. This parameter may also be an important prognostic factor that has to be looked at in a prospective manner.

A limitation of our study is its retrospective character, although as the aim was to identify prognostic factors we do not think that this affects the results. Another limitation is the heterogeneity of the diseases found in our patients, meaning that disease-specific factors might influence the visual result in each case. However, the finding that macular oedema associated with different diseases responded to the same treatment points to the possibility of a common pathological pathway, and hence common prognostic factors.

We did not perform OCT on most patients in this study. It may be possible to study OCT scans before IVTA injections in order to identify additional prognostic factors.

In summary, patients with clinical or angiographic evidence of CME, as well as pseudophakic patients, are more likely to show visual acuity improvement after undergoing IVTA for macular oedema.

\section{References}

1 Negi AK, Vernon SA, Lim CS, Owen-Armstrong K. Intravitreal triamcinolone improves vision in eyes with chronic diabetic macular oedema refractory to laser photocoagulation. Eye 2005; 19: 747-751.

2 Jonas JB, Degenring RF, Kamppeter BA, Kreissig I, Akkoyun I. Duration of the effect of intravitreal triamcinolone acetonide as treatment for diffuse diabetic macular edema. Am J Ophthalmol 2004; 138: 158-160.

3 Bashshur ZF, Ma'luf RN, Allam S, Jurdi FA, Haddad RS, Noureddin BN. Intravitreal triamcinolone for the management of macular edema due to nonischemic central retinal vein occlusion. Arch Ophthalmol 2004; 122: 1137-1140.

4 to-Pedre E, Hernaez-Ortega MC. Intravitreal triamcinolone acetonide in eyes with cystoid macular edema associated with central retinal vein occlusion. Am J Ophthalmol 2004; 137: 596.

5 Karacorlu M, Ozdemir H, Karacorlu S. Intravitreal triamcinolone acetonide for the treatment of chronic pseudophakic cystoid macular oedema. Acta Ophthalmol Scand 2003; 81: 648-652.

6 Karacorlu M, Mudun B, Ozdemir H, Karacorlu SA, Burumeck E. Intravitreal triamcinolone acetonide for the treatment of cystoid macular edema secondary to Behcet disease. Am J Ophthalmol 2004; 138: 289-291.

7 Sutter FK, Gillies MC. Intravitreal triamcinolone for radiation-induced macular edema. Arch Ophthalmol 2003; 121: 1491-1493.

8 Scott IU, Flynn Jr HW, Rosenfeld PJ. Intravitreal triamcinolone acetonide for idiopathic cystoid macular edema. Am J Ophthalmol 2003; 136: 737-739.

9 Gillies MC, Simpson JM, Luo W, Penfold P, Hunyor AB, Chua $\mathrm{W}$ et al A randomized clinical trial of a single dose of intravitreal triamcinolone acetonide for neovascular agerelated macular degeneration: one-year results. Arch Ophthalmol 2003; 121: 667-673.

10 Bakri SJ, Beer PM. The effect of intravitreal triamcinolone acetonide on intraocular pressure. Ophthalmic Surg Lasers Imag 2003; 34: 386-390.

11 Jonas JB, Kreissig I, Degenring RF. Endophthalmitis after intravitreal injection of triamcinolone acetonide. Arch Ophthalmol 2003; 121: 1663-1664.

12 Nelson ML, Tennant MT, Sivalingam A, Regillo CD, Belmont JB, Billson F. Infectious and presumed noninfectious endophthalmitis after intravitreal triamcinolone acetonide injection. Retina 2003; 23: 686-691.

13 Adamis AP. Is diabetic retinopath an inflammatory disease? Br J Ophthalmol 2002; 86: 363-365.

14 Sutter FK, Simpson JM, Gillies MC. Intravitreal triamcinolone for diabetic macular edema that persists after laser treatment: three-month efficacy and safety results of a prospective, randomized, double-masked, placebocontrolled clinical trial. Ophthalmology 2004; 111: 2044-2049. 